\title{
Dual abrogation of MNK and mTOR: a novel therapeutic approach for the treatment of aggressive cancers
}

\begin{abstract}
Targeting the translational machinery has emerged as a promising therapeutic option for cancer treatment. Cancer cells require elevated protein synthesis and exhibit augmented activity to meet the increased metabolic demand. Eukaryotic translation initiation factor $4 \mathrm{E}$ is necessary for mRNA translation, its availability and phosphorylation are regulated by the PI3K/AKT/mTOR and MNK1/2 pathways. The phosphorylated form of eIF4E drives the expression of oncogenic proteins including those involved in metastasis. In this article, we will review the role of elF4E in cancer, its regulation and discuss the benefit of dual inhibition of upstream pathways. The discernible interplay between the MNK and mTOR signaling pathways provides a novel therapeutic opportunity to target aggressive migratory cancers through the development of hybrid molecules.
\end{abstract}

First draft submitted: 9 March 2017; Accepted for publication: 12 May 2017; Published online: 25 August 2017

Keywords: cancer $\bullet$ cell migration $\bullet$ elF4E $\bullet$ hybrid drugs $\bullet$ kinase inhibitors $\bullet$ MNK1/2 - $\mathrm{mTOR} \bullet$ resistance $\bullet$ signaling $\bullet$ translation

\section{Translation initiation: an overview}

Gene expression is regulated at both the transcriptional and translational levels. Translational control is critical for maintaining protein levels within the cell and achieving homeostasis. The majority of mRNA is translated by the cap-dependent mechanism. This is primarily regulated at the level of the initiation phase and involves eukaryotic initiation factors and accessory proteins (summarized in Figure 1 and reviewed in [4]). Initiation factors coordinate vital checkpoints during this process and determine both whether a specific mRNA is translated and the rate of its translation, therefore, contributing to the total abundance of specific protein within the cell [1].

Translation initiation begins when the eIF2-GTP complex binds to the methionyltransfer RNA, forming a ternary complex that associates with the $40 \mathrm{~S}$ ribosomal subunit. Additional factors such as eIF5, eIF3,
eIF1 and eIF1A promote ternary complex binding, leading to the construction of the $43 \mathrm{~S}$ preinitiation complex. eIF4E, eIF4G and eIF4A, also known as the cap-binding complex, bind to the $\mathrm{m}^{7} \mathrm{GTP}$ cap structure at the 5 'end of the mRNA.

eIF4E recognizes the 5 'cap necessary for the start of cap-dependent translation initiation. The structure of eIF4E resembles a cupped hand; the concave surface of eIF4E binds to the cap and the convex surface interacts with eIF4G $[2,3]$. The presence of the cap structure on eukaryotic mRNA facilitates the recruitment of eukaryotic initiation factors to allow ribosome binding and initiation at the correct start site [2]. eIF4G functions as a scaffold protein, necessary for the coordinated attachment of translation initiation machinery and the ribosome to the 5 'end of the mRNA [4]. It is a multidomain phosphoprotein that contains binding sites for eIF4E, eIF4A, MNK1/2 and PABP [5].
Ella Lineham*,1, John Spencer ${ }^{2}$ \& Simon J Morley ${ }^{1}$

'Department of Biochemistry, School of Life Sciences, University of Sussex, Brighton, BN1 9QG, UK

2Department of Chemistry, School of Life Sciences, University of Sussex, Brighton, BN1 9QJ, UK

*Author for correspondence:

e.lineham@sussex.ac.uk newlands press part of 
Review Lineham, Spencer \& Morley

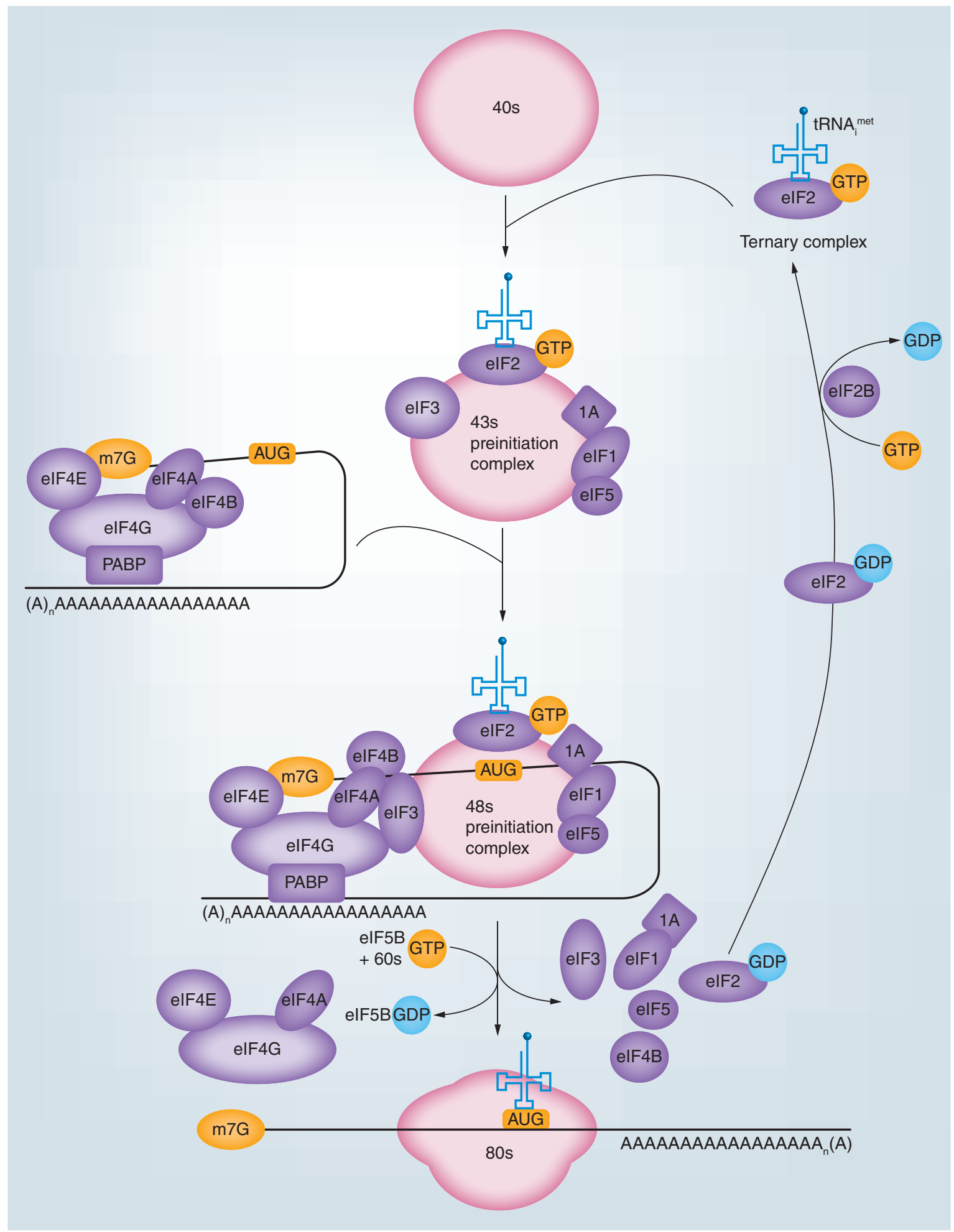


Figure 1. Eukaryotic cap-dependent translation initiation (see facing page). Eukaryotic initiation factors (elFs) such as elF1, elF1A and eIF3 form a 435 pre-initiation complex (PIC), together with the ternary complex (elF2Met-tRNA-GTP), and the $40 \mathrm{~S}$ subunit. After binding of the ternary complex to the $40 \mathrm{~S}$ subunit, elF5 interacts with elF2. The mRNA is activated by the binding of the elF4F complex (elF4A, elF4E and elF4G) to the cap and PABP to the poly(A) tail, circularising the mRNA. The interaction of elF3/ elF5 with elF4G facilitates the binding of the 435 PIC near the cap, forming the $48 \mathrm{~S}$ initiation complex. This $48 \mathrm{~S}$ initiation complex scans the $5^{\prime}$ leader for the AUG codon in an ATP-dependent reaction, partial hydrolysis of elF2-GTP to elF2-GDP also occurs. Upon start codon recognition, elF1/ elF1A dissociates, allowing the release of elF2-GDP +Pi. The joining of the 60S ribosomal subunit is promoted by eIF5B, along with the release of other elFs to yield the final 805 initiation complex and translation can then begin. eIF2B, a guanine nucleotide exchange factor, converts the inactive eIF2-GDP to the active eIF2-GTP allowing the ternary complex to be reformed.

Circularization of the mRNA occurs when eIF4G binds to PABP, bringing together the $5^{\prime}$ and $3^{\prime}$ ends of the mRNA, creating the $48 \mathrm{~S}$ preinitiation complex. Upon recognition of the correct start codon by ribosomal scanning, the eIF2-GTP complex undergoes hydrolysis, triggering its release from the $48 \mathrm{~S}$ complex along with other eIFs. The dissociation of these factors allows the binding of the $60 \mathrm{~S}$ ribosomal subunit and the formation of the $80 \mathrm{~S}$ ribosomal complex. The process of peptide bond synthesis can then begin $[4,6]$.

\section{eIF4E \& its role in cancer}

eIF4E is a critical component of the eIF4F complex and the level of eIF4E expression is an important determinant in the translation of mRNAs [7]. Although translation initiation is considered to be the ratelimiting step of protein synthesis and the primary level of modulation, recent work has found that substantial regulation also occurs at the elongation stage [8]. Cellular mRNAs differ in the amount of eIF4E required for their translation, homeostasis is achieved by maintaining the translation of essential mRNAs and limiting the translation of proto-oncogenes. eIF $4 \mathrm{E}$ is a general translation factor but has the potential to selectively enhance the translation of mRNAs that leads to the production of malignancy-associated proteins [9]. The generation of an eIF4E-haplo-insufficient mouse has challenged the dogma that eIF4E dose is limiting for normal development. Truitt et al. found that a 50\% reduction in eIF4E expression was compatible with regular development and global protein synthesis, revealing that eIF4E is present at levels exceeding those required for normal translational control. Interestingly, these mice were physiologically normal but resistant to neoplastic transformation. eIF4E appears to be limiting for the expression of oncogenic proteins and further enforces the importance of eIF4E in cancer development $[7,8]$.

The overexpression of eIF4E leads to an increase in the translation of a subset of mRNAs that favors oncogenesis, in particular those with highly structured 5'untranslated regions [10]. Housekeeping mRNAs, for example, cytoskeleton proteins, require a low level of eIF4E, whereas proto-oncogenic and prosurvival proteins such as c-Myc, cyclin D1, Pim-1, survivin, Bcl-2, VEGF have a much higher dependency on eIF4E for translation [11,12]. These mRNAs are termed as 'weak mRNAs' and are greatly influenced by an increase in eIF4E levels, observed in 30\% of human cancers [13-15]. The availability of eIF4E is regulated by $4 \mathrm{E}$-binding proteins, which compete with eIF $4 \mathrm{G}$ for a common surface to bind to eIF4E $[4,16,17]$.

A recent study proposes that the mechanism by which eIF4E promotes the translation of specific mRNAs is by increasing their cytoplasmic levels and therefore the capacity of these mRNAs to associate and form the eIF4F complex. eIF4E stimulates the nuclear transport of mRNAs housing an eIF4E-sensitivity element. Notably, these mRNAs encode proteins associated with growth and malignancy [18]. For example, eIF4E regulates the expression of E3 ubiquitin-protein ligase, an important negative regulator of $\mathrm{p} 53$. Overexpression of eIF4E promotes the export of the mRNA into the cytoplasm in an MNK1-dependent manner $[19,20]$.

The oncogenic potential of eIF4E has been recapitulated both in vitro and in vivo. The phosphorylation of eIF4E is required for its role in mRNA export from the nucleus and cellular transformation [21]. Recent studies have found that high levels of eIF4E-P coincided with poor clinical outcome in human cancers [22-24]. MNK1 and MNK2 are serine/threonine protein kinases responsible for the phosphorylation of S209 on eIF4E [25]. The phosphorylation of eIF4E correlates with the increase in mesenchymal markers such as $\mathrm{N}$-cadherin, fibronectin and vimentin, along with the acquisition of invasive properties [26].

It has been observed that overexpression of eIF4E leads to the transformation of immortalized murine fibroblasts and human epithelial cells $[1,27,28]$. High levels of eIF4E were also shown to promote the aberrant expression of tumor-related proteins by positively regulating the expression of VEGF in a head and neck squamous cell carcinoma cell line (HNSCC). Low levels of eIF4E were found to downregulate VEGF and matrix metalloproteinases, simultaneously, in colon cancer. MMP-2 promotes tumor invasiveness by degrading type IV collagen, a vital component of the 
basement membrane. The increase in expression frequency of eIF4E, VEGF-C, E-cadherin and MMP-2 was associated with the depth of tumor invasion, lymph node metastasis and clinical stage in colorectal cancer [29].

Deregulation of mRNA translation can result from the overactivation of various upstream kinases such as PI3K or AKT, along with the inactivation of tumor suppressors, phosphatase and tensin homo$\log$ (PTEN), tuberous sclerosis complex 1 (TSC1) or tuberous sclerosis complex 2 (TSC2). eIF4E acts at a convergence point of two important signaling pathways in the cell and these upstream mutations can lead to the translation of a subset of oncogenic mRNAs [30]. This evidence highlights the importance of eIF4E in metastasis.

Metastasis of cancer cells and the formation of secondary tumors are extremely problematic in the clinic, accounting for approximately $90 \%$ of human cancer deaths [31]. Cancer cells require specific and rapid gene expression to invoke this invasive phenotype, which has the capacity to bypass tissue barriers, intravasate into the bloodstream and seed at distal secondary sites [1]. Studies have found initiation factors at sites of active translation near the leading edge of migrating fibroblasts. This suggests a mechanism for spatial translational control that could be exploited by cancer cells during metastasis [32].

Cellular migration is initiated by the integration of signals derived from extracellular cues, interactions with the extracellular matrix and contact with adjacent cells. Migration begins when cells polarize by rearrangement of their actin cytoskeleton, a process driven by the action of Rho GTPases [33]. Cells extend cellular membrane protrusions, comprising broad lamellipodia or spike-like filopodia toward the external attractant [34]. These protrusions are stabilized by focal adhesions that link the actin filaments to ECM proteins [35].

Experimental evidence has shown that repression of eIF4E effectively prevented cell migration in MDAMB-231 cells and also sensitized these cells to chemotherapy [36]. Disrupting cellular migration is a promising therapeutic option for the treatment of cancer [37].

\section{MAPK-interacting kinases}

MAPK-interacting kinase 1 is a serine/threonine protein kinase that lies downstream of both p38MAPK and ERK pathways (Figure 2), which is often subject to upregulation in tumor cells [9]. These upstream kinases activate mouse MNK1 via phosphorylation on Thr 197/202 [21]. Recent work shows that MNK1 can also be phosphorylated by p90 ribosomal protein S6 kinase (p90 ${ }^{\text {rsk }}$ ), in a mechanism that confers trastuzumab resistance in HER-2 positive breast cancers [38]. The MNKs associate with the C-terminus of eIF4G, a vital interaction that brings the kinase into close enough proximity to phosphorylate eIF4E on Ser209 [5,39]. This phosphorylation enhances translation of specific mRNAs involved in cell survival [25]. Recent findings in a mouse lymphoma model demonstrate that the phosphorylated form of eIF4E is required for the translation of a subset of mRNAs that oppose apoptosis and favor tumorigenesis $[13,21,30,40-42]$. The role of the MNKs has been linked to the pathogenesis of many cancers [43,44]. PAK2 can interfere with the MNK1/2eIF4G interaction by phosphorylating the MNKs on specific threonine and serine residues resulting in decreased affinity for eIF4G [21].

There are four human MNK isoforms; each MNK gene produces both a long isoform and a short isoform through variation in splicing $[45,46]$. The $\mathrm{N}$-termini

Figure 2. Key components of major signaling pathways affecting protein translation (see facing page). Growth factors bind to receptors including Receptor Tyrosine Kinases (RTKs) in the cell membrane, stimulating a cascade of signals. The activated RTK is phosphorylated on its tyrosine residues, Grb2 docks the phosphotyrosine residues via its $\mathrm{SH} 2$ domain and subsequently binds the guanine nucleotide exchange factor, Sos, by its SH3 domains. Activated Sos promotes the release of GDP from Ras, enabling the binding of GTP to form Ras-GTP. Activated Ras recruits Raf to the plasma membrane, where it phosphorylates and activates MEK1/2, which in turn activates ERK. ERK phosphorylates and activates many proteins including MNK1/2 and RSK. In addition, ERK phosphorylates and inactivates TSC2. MNK1/2 lie at the convergence point of both the p38MAPK pathway and ERK pathways and upon activation, phosphorylate elF4E. Class I PI3 kinases are activated by RTKs resulting in the conversion of PIP2 to PIP3, a secondary messenger that is essential for AKT translocation to the plasma membrane. The level of PIP3 is negatively regulated by the tumour suppressor, PTEN. AKT is partially activated by PDK1 and becomes fully activated upon phosphorylation at Ser473, a process that can be catalysed by multiple proteins. mTOR forms two distinct multiprotein complexes, mTORC1 and mTORC2. In response to stimulation, activated AKT phosphorylates and inactivates the TSC1-TSC2 complex, which allows Rheb-GTP to activate mTORC1 on the lysosome. Activated mTORC1 stimulates protein translation by phosphorylating 4E-BP1 on several residues, releasing elF4E allowing it to participate in translation initiation. In addition to phosphorylating other translational targets, mTORC1 also phosphorylates p70S6 kinase (p70S6K), which becomes fully activated following PDK1-mediated phosphorylation. p70S6K targets a number of proteins that control protein translation, including ribosomal protein S6, elF4B and pdcd4. Low glucose levels and hypoxic conditions result in high AMP levels and lead to AMPK activation and subsequent mTORC1 inhibition. mTORC2 promotes cell survival through the phosphorylation of AKT on serine 473. 


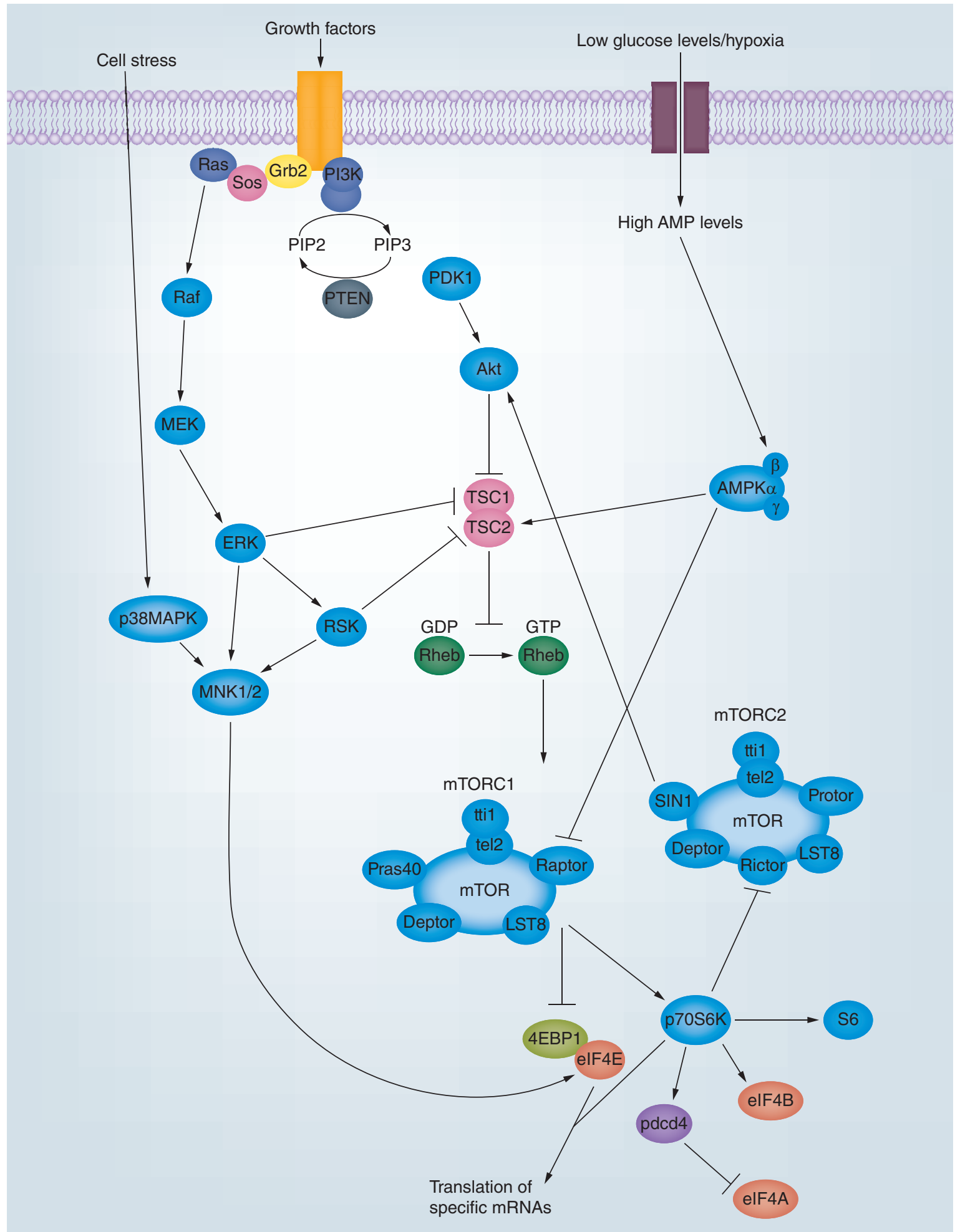


of all four isoforms are similar; each one containing a nuclear localization signal and an eIF4G-binding site. The central region houses a kinase domain [9]. The C-terminal region of the isoforms differs; the longer isoforms (Mnk1a and Mnk2a) contain a MAPK binding site, which is lacking in the shorter isoforms (Mnk1b and Mnk2b) [45,46]. The MNK1a MAPKbinding domain interacts with both P38MAPK and ERK1/2, whereas the MNK2a MAPK-binding domain only binds to ERK1/2. This variation is reflected in a single amino acid change in the MAPKbinding site and determines the difference observed in their regulation [47]. MNK1a has low basal activity, and is activated and tightly regulated by ERK and p38 kinases in response to mitogens and stress [25,48]. MNK2 displays high basal activity and is predominantly regulated by ERK1/2, although MNK2a is regulated by mTORC1 through at least one site in its C-terminal region $[49,50]$.

There is speculation as to why mammalian cells possess two kinases that perform the same function but show a variation in basal activity. Data show that changes in the phosphorylation status of eIF4E in response to growth factors and stress are MNK1-dependent.

MNK2 is therefore postulated to maintain a basal level of eIF4E phosphorylation under conditions of starvation, where MNK1 is inactive, and ensure the synthesis of housekeeping proteins [47].

The subcellular location of MNK isoforms likewise differs, MNK1a contains a nuclear export signal allowing its transport to the cytoplasm. MNK1b lacks a nuclear export signal, and is localized both in the nucleus and cytoplasm, whereas MNK2a and MNK2b are predominantly nuclear $[19,51]$. Both MNK1 and MNK2 mRNAs have been found ubiquitously expressed in a variety of tissues by northern blot analysis. Fan $e t$ al. recently observed a considerably higher percentage of active phospho-MNK in astrocytomas, further endorsing the role of active MNK in cancer [47,52]. High levels of phosphorylated MNK1 are also observed in HER-2 positive breast cancer and in glioblastoma multiforme primary tumors. Silencing of MNK1 through the infection of a U87MG glioma cell line with a small hairpin RNA attenuated eIF4E phosphorylation and reduced proliferation [38,53].

MNK1/2 present an attractive potential therapeutic target as they act at the convergence point of two critical signaling pathways viz; p38MAPK and ERK. The MNK1/2 substrate, eIF4E, is also regulated by the mTORC1 pathway, which is activated in about $70 \%$ of cancers $[9,21,30,54]$. Mice with a targeted deletion of MNK1 and MNK2 exhibit total abolishment of eIF4E phosphorylation and do not display developmental or reproductive defects [21,41]. Additionally, knock-in mice expressing a mutant form of eIF4E (S209A) are unable to be phosphorylated by MNK1/2 and show resistance to neoplastic transformation by $\mathrm{C}-\mathrm{myc}$, constitutively active Ras and PTEN loss-induced prostate cancer. These mice also exhibit a reduction in vascular endothelial growth factor (VEGF) and matrix metalloprotease 3 (MMP3), associated with tumour invasiveness [40]. Clinical development of MNK inhibitors may provide a means to selectively target cancer cells, as MNKs are dispensable for normal development [55]. The treatment of acute myeloid leukaemia (AML) cell lines with MNK inhibitor, cercosporamide (Figure 4C) resulted in suppression of MNK kinase activity and leukemic progenitor cell growth. In addition, antileukemic effects were amplified when cercosporamide was used in conjunction with mTORC1/2 inhibitor, rapamycin (Figure 4A) [56]. Recent findings found that MNK kinases act as negative feedback regulators in response to chemotherapy and hence, contribute to chemoresistance. The level of eIF4E-P significantly increased in cancer patients during treatment with doxorubicin and cyclophosphamide, the standard treatment for advanced stage breast cancer. The siRNA knockdown or pharmacologic inhibition of MNK1/2 was found to enhance the chemotherapeutic response in both AML and advanced stage breast cancer cell lines $[24,56]$.

The crystal structures of MNK1 and MNK2 are available in the DFD-out (Asp-Phe-Asp) conformation (Figure 3). Their catalytic domains share 78\% sequence identity and the active sites are highly conserved [25,57]. MNK1 and MNK2 display the canonical bilobal arrangement of the ATP-binding cleft sandwiched in between the C-terminal and $\mathrm{N}$-terminal lobes. The $\mathrm{C}$-terminal lobe is predominantly $\alpha$-helical and is composed of the activation segment, the P-loop and the catalytic loop; elements required for substrate binding and phosphate transfer. Kinase activation occurs when the activation loop is phosphorylated, resulting in a conformational change. The P-loop enables the optimal alignment of the phosphoryl groups of ATP, while the catalytic loop encompasses highly conserved residues vital for phosphotransfer. The $\mathrm{N}$-terminal lobe comprises five $\beta$-strands and the regulatory $\alpha \mathrm{C}$-helix. The $\alpha \mathrm{C}$-helix is misaligned in inactive kinases and its correct alignment is required for ATP binding, and hence kinase activity $[58,59]$.

The conserved DFD motif marks the beginning of the activation loop $[58,60]$. The DFD motif (Asp191Phe192-Asp193 in MNK1 and Asp226-Phe227Asp228 in MNK2) has less affinity for ATP than the 


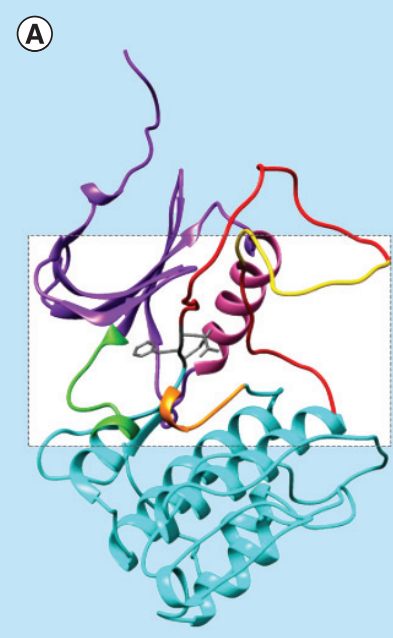

(B)

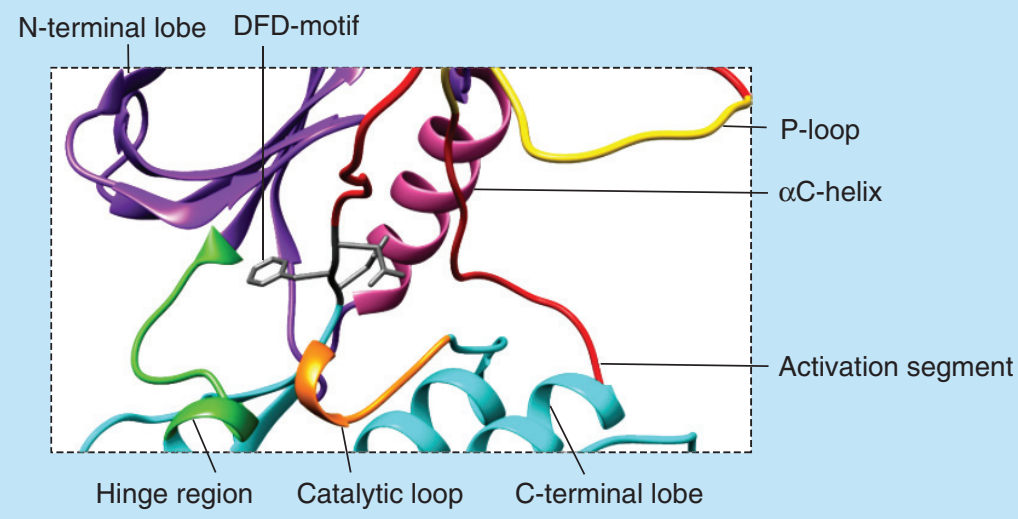

Figure 3. Apo-form of Mnk1 in inactive conformation DFD-Out conformation (PDB ID: 2HW6). Structural elements colored accordingly: N-terminal lobe (purple), C-terminal lobe (cyan), aC-helix (pink), hinge region (green), catalytic loop (orange), DFD-motif (grey), activation segment (red) and p-loop (gold). Auto-inhibition due to Phe230 in the activation segment pushing out Phe192 away from DFD towards the ATP binding site, obstructing the ATP binding pocket. Molecular graphics and analyses were performed with the UCSF Chimera package [123]. DFD: Asp-Phe-Asp; UCSF: University of California, CA, USA.

For color figures see www.future-science.com/doi/full/10.4155/fmc-2017-0062

equivalent DFG motif present in other kinases. This is due to a $180^{\circ}$ rotation relative to the DFG motif, which locks the kinase in the DFD-out conformation. This unique structure coupled with specific regions of the catalytic domain (insertions 1-3) distinguishes the Mnks from other kinases and provide an opportunity to design specific Mnk inhibitors [9,61].

\section{mTOR}

Mammalian target of rapamycin is a Ser/Thr protein kinase complex that lies downstream in the PI3K/ AKT signaling pathway. mTOR, known as the master regulator of the cell, responds to signals from extracellular stimuli, amino acid availability, oxygen and energy status of the cell. Signaling is stimulated by growth factors and mitogens.

mTOR belongs to the phosphatidylinositol 3-kinase family, and forms two multiprotein complexes; mTORCland mTORC2. The complexes both contain mTOR kinase but differ in the associated regulatory proteins. mTORC1 is defined by the regulatory-associated protein of mTOR (RAPTOR) whereas mTORC2 is defined by the rapamycin-insensitive companion of mTOR (RICTOR; Figure 2) [62].

mTORC1 is activated by multiple growth factors, insulin and nutrients through the PI3K/AKT pathway and has a central role in stimulating protein synthesis $[63,64]$. The interaction between eIF4G and eIF4E in the eIF4F complex is inhibited by $4 \mathrm{E}$-binding proteins. $4 \mathrm{E}-\mathrm{BP} 1$ competes with eIF4G for a shared binding site on eIF4E. The interaction strength of 4E-BP1 binding to eIF4E depends on the phosphorylation status of 4E-BP1 [65]. Hypo-phosphorylated 4E-BP1 binds strongly to eIF4E whereas hyper-phosphorylated 4E-BP1 weakens its interaction with eIF4E $[4,16,66]$. 4E-BP1 contains at least seven sites of phosphorylation, of which four are known to be regulated by mTORC1 and associated signaling pathways [66]. Activated mTORC1 remains at the mRNA 5'cap where it can promote cap-dependent mRNA translation by phosphorylating and inactivating 4E-BP1, activating $\mathrm{p} 70 \mathrm{~S} 6 \mathrm{~K}$ and increasing overall protein synthesis by stimulating rRNA transcription and ribosome biogenesis $[67,68]$. mTORC1 also has a prominent role in lipid synthesis, required for the generation of cellular membrane during proliferation [67]. Cancer cells often hijack the PI3K/AKT/mTOR pathway in order to meet the demands of increased growth rate, as observed in patients with acute myeloid leukemia [69-71].

mTORC1 integrates signals from the cellular environment with the translational apparatus by phosphorylating p70S6K; a subsequent phosphorylation by PDK1 leads to its full activation and its release from eIF3 [69,72]. Active p70S6K subsequently phosphorylates ribosome protein S6, eIF4G, eIF4B, pdcd 4 and fragile $\mathrm{X}$ mental retardation protein, an mRNAbinding protein [73,74]. mTORC1 also responds to the energy status of the cell, a decrease in the ATP/ AMP ratio activates AMPK, which suppresses mTORC1. Hypoxic conditions induce the expression 
of protein regulated in development and DNA damage response 1 (REDD1), a protein that modulates TSC2 activity, leading to inhibition of mTORC1 [64]. mTORC1 is a negative regulator of autophagy, an important cellular process in which damaged organelles and intracellular pathogens are degraded inside lysosomes [69]. It is stimulated by branched chain amino acids through the RAS-related GTP-binding proteins, (RAG) family of GTPases, which recruit mTORC1 to lysosomes where it becomes activated by Rheb. mTORC1 phosphorylates unc-51 like autophagy activated kinase (ULK1) and its positive regulator,

\section{(A) Allosteric inhibitors of mTORC1}

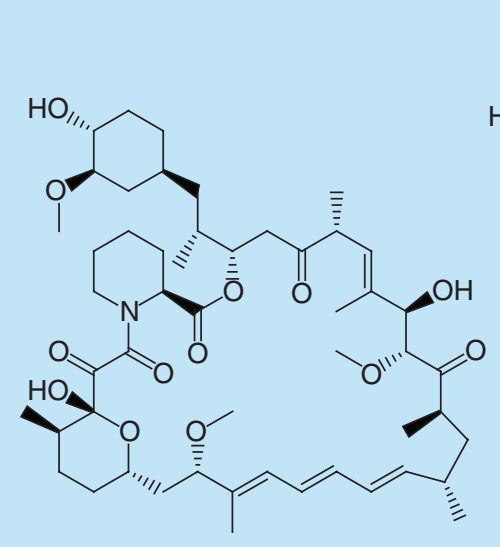

Sirolimus (rapamycin)

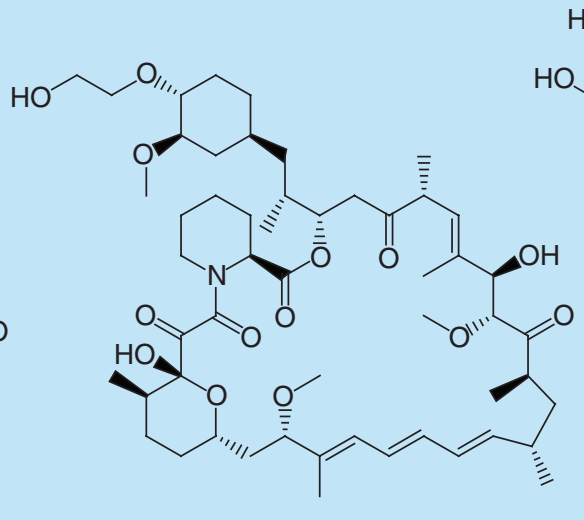

Everolimus

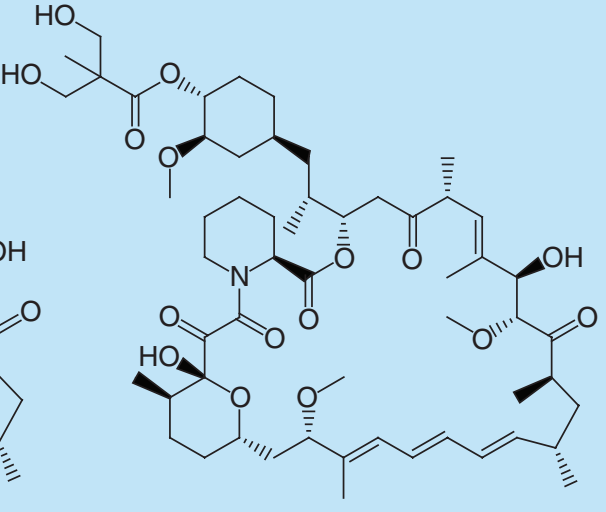

Temsirolimus
(B) Inhibitors of mTOR active site<smiles>COc1ccc(-c2ccc3c(N4CCOC[C@H]4C)nc(N4CCOC[C@H]4C)nc3n2)cc1CO</smiles>

PP242<smiles>Nc1ncnc2[nH]nc(Nc3ccc(F)cc3)c12</smiles>

CGP57380<smiles>CC(=O)C1=C(O)C=C2Oc3c(C(N)=O)c(O)cc(O)c3[C@@]2(C)C1=O</smiles>

Cercosporamide

\section{(D) Hybrid agents}<smiles></smiles>

Estramustine

CUDC-101

Dual action HDACi/VEGFR2i

Figure 4. Inhibitors. (A) Allosteric inhibitors of mTOR, (B) catalytic site inhibitors of mTOR, (C) catalytic site inhibitors of Mnk1/2 and (D) hybrid agents. 
autophagy-related protein 13 (ATG13), inhibiting autophagosome formation $[67,75,76]$. Signaling pathways involving mTORC1 are complex, and there are many negative loops which add a further level of regulation. One such loop involves the phosphorylation of insulin receptor substrate 1 , either directly by activated mTORC1 or via mTORC1 activated p70S6K. This leads to its degradation and results in a decrease in PI3K/AKT signaling and subsequently a downregulation of mTORC1 activity [75].

The role and regulation of mTORC2 remain ambiguous, partly due to the lack of an mTORC2 selective inhibitor. mTORC2 is thought to be involved in cell survival and cell-cycle progression through phosphorylation of Ser473 on AKT, and through activation of serum- and SGK and PKC $[9,62,67,75]$. Recent advancements, in yeast, using reverse chemical genetics have allowed specific mTORC2 inhibition, although an analogous system in mammalian cells has yet to be established [77]. Genetic studies involving the deletion of the RICTOR subunit, an essential scaffold protein, results in mTORC2 disassembly and loss of function. However, unlike acute chemical inhibition, genetic studies permit adaption to occur, often confounding results. For example, phosphorylation of AKT Ser473 was observed in RICTOR-deficient cells. A proposed explanation is the adaptation of the cell to the genetic change allowing the phosphorylation of AKT Ser473 by other kinases such as DNA-PKCS [78,79].

\section{mTOR \& its role in cancer}

Inactivating mutations in the tumor suppressor gene, PTEN, a phosphatase that antagonizes PI3K function are a common feature in cancer cells [71]. This causes an upregulation of PI3K activity in the cell and constitutive stimulation of the PI3K/AKT/mTOR pathway $[42,80]$. Activated mTORC1 has a multitude of consequences in cancer development. mTORC1dependent phosphorylation of 4E-BP1 causes its release from eukaryotic initiation factor 4E. eIF4E forms part of the eIF4F complex (with the helicase eIF4A and the scaffold protein, eIF4G) and the level of eIF4E expression is a critical determinant in the translation of oncogenic mRNAs [7,8]. Ribosome profiling studies reveal that some mTOR translationally regulated mRNAs possess a 5'terminal oligopyrimidine tract, also termed as 5'TOP [81,82]. These mRNAs include YB1, vimentin, MTA1 and CD44, all of which have a significant role in the process of metastasis. Hyperactive mTOR signaling has a profound effect on the translational landscape of cancer cells by positively regulating this four-gene invasion signature $[63,83]$.
A hallmark of cancer cell reprogramming is the switch to aerobic glycolysis metabolism. Activated mTORC1 increases the transcription and translation of hypoxia inducible factor (HIF1 $\alpha$ ), which in turn regulates glycolytic genes, enabling the tumor cell to meet the high demands required for survival and progression $[70,84]$. There is also evidence that both mTORC1 and mTORC2 are implicated in the epithelial-mesenchymal transition (EMT) [85]. EMT in relation to cancer can be defined as the conversion of differentiated epithelial cells into migratory mesenchymal cells through the loss of epithelial markers and the gain of mesenchymal markers [86]. This is thought to occur in part, through the modulation of genes that code for proteins associated with cytoskeleton rearrangement, such as RhoA, Rac1 and Cdc42 GTPases. mTORC1 mediated signaling also plays a role in the phosphorylation of focal adhesion proteins and the promotion of cell motility [33].

Deregulation of the mTOR pathway is correlated with poor clinical outcome and drug resistance [84]. There are currently only two US FDA approved mTOR inhibitors available for cancer treatment (temsirolimus and everolimus). However, both have had limited success in the clinic due to the activation of negative feedback loops which trigger activation of MNK1. This effect of targeted mTORC1 inhibition was confounded by a recent study of rapamycin treated myeloma cells, which resulted in the increased phosphorylation of MNK1 along with its target, eIF4E [21,42]. The multiplicity of on-target side effects also limits the use of rapamycin due to mTORC1's wide variety of cellular functions [87].

\section{Interplay between the mTOR \& Mnk/elF4E pathways}

There is some evidence for a compensatory feedback mechanism linking the AKT/mTOR pathway and the MNK/eIF4E pathway. Both pathways are required for efficient protein translation and a fine balance needs to be achieved for cellular homeostasis. This was reported in both prostate and lung cancer, where the downregulation of one pathway correlated with the activation of the other, which subsequently supported cell proliferation and cancer survival $[41,42]$.

This interplay between both MNK and mTOR pathways has also been reported clinically. Rapamycin, a naturally occurring macrolide, originally purified from Streptomyces hygroscopicus was initially used in transplant patients to prevent allograft rejection [22,88,89]. Synthetic analogs of rapamycin, such as temsirolimus and everolimus have been used to treat cancer patients with hyperactive PI3K/AKT/mTOR signaling. 
Rapamycin and rapalogs are allosteric inhibitors of mTORC1, and work by recruiting FKBP-12, an accessory protein, to the FRB domain of mTOR. The formation of this drug-protein complex causes a conformational change in $\mathrm{mTORC1}$, distal from the kinase domain, leading to its inhibition [69,90]. Recent structural studies have further elucidated the mechanism by which rapamycin inhibits mTORC1 [91]. Complex feedback loops involving activation of PI3K and MAPK signaling have limited the success of mTOR inhibitors in the clinic $[30,69]$. Several studies have shown that rapamycin treatment increases the level of eIF4E phosphorylation and AKT activation [42,92-94], contributing to the development of resistance to mTOR inhibitors [95].

Cancer cells have adapted to mTOR inhibition by downregulating the expression and translation of 4E-BPs [96]. Increases in the eIF4E-4E-BP1 ratio, limits the effect of mTOR inhibitors [69]. Chronic mTOR inhibition in SW620 colon cancer cells with superior catalytic site inhibitors such as AZD8055, resulted in an increase in eIF4E expression. This shift in signaling promotes cap-dependent translation and appears to be more instrumental in cancer progression in comparison to S6K signaling $[64,75,83]$.

Acute treatment with active site inhibitors of mTOR induces autophagy, which is a double-edged sword in relation to tumor development and can be both antitumorigenic or protumorigenic depending on the stimulus $[67,69]$. Autophagy can induce a prosurvival phenotype in cancer cells through maintaining cellular energy levels in conditions of starvation and stress by degrading intracellular organelles [97].

Targeting eIF4E signaling downstream of mTOR by inhibiting MNK kinases may prevent feedback initiation [30]. Simultaneous inhibition of MNK1/2 kinase and mTORC1 suppressed cell-cycle progression and blocked proliferation in both PC-3 and glioblastoma cell lines $[41,42]$. This effect was increasingly pronounced when inhibitors were added in combination as opposed to being employed as a monotherapy, indicating the importance of dual abrogation of such pathways [41,42]. A recent study also found that the MNK inhibitor, CGP57380, attenuates RAD001-activated eIF4E phosphorylation in non-small-cell lung cancer cells. Such a combination of inhibitors augmented the antitumor response by inhibiting cell proliferation and inducing apoptosis [98].

\section{Therapeutic targeting \& the concept of hybrid inhibitors}

Cancer is notoriously heterogeneous and difficult to treat. Each cell constitutes a different genetic make-up, due to variations in the pattern of active oncogenes and inactive tumor suppressors. A given drug may successfully eliminate cells harboring a specific mutation, however, cells driven by alternative pathways will survive [22]. Even clonally derived tumor cells exhibit variation in drug resistance [99]. The complexity of cellular signaling means that the traditional single treatment approach is often ineffective, and inhibition of multiple targets is required to stay one step ahead of the tumor cell $[80,100,101]$. Advances in personalized medicine and genomic screening have enabled the identification of specific mutations in an individual patient. This enhanced knowledge can then be used to tailor treatment to target oncogene addictions, exploit synthetic lethalities and establish the most suitable combination of therapies $[99,102]$.

The failure to respond to treatment results from a combination of host factors and genetic alterations in the cancer cell. These host factors can include poor absorption, rapid metabolism and excretion, along with the inability to deliver the drug to the site of the tumor. Bulky solid tumors and high molecular weight compounds often account for low penetrance. Elderly patients frequently exhibit poor tolerance, which leads to sub-optimal dosing and the development of resistance, allowing the cancer to survive [99].

Currently, the only FDA approved approach for the inhibition of the PI3K/AKT/mTOR pathway is through the use of mTOR allosteric inhibitors, everolimus and temsirolimus (see Figure 4). These rapalogs have been effective in the treatment of renal cell carcinoma but have significant disadvantages due to their feedback activation of AKT [69,84,103]. A new generation of mTOR catalytic site inhibitors holds much promise due to their potent inhibition of both mTORC1 and mTORC2, thus attenuating the feedback mechanism involving AKT phosphorylation [104]. These inhibitors are ATP analogs that contain a heterocyclic structure to exploit the adenine-binding pocket and can form hydrogen bonds with the hinge region of the kinase [105]. Type II inhibitors introduce additional specificity by binding not only the ATP pocket but also an adjacent allosteric pocket $[106,107]$. The recently solved crystal structure of the mTOR kinase domain in complex with ATP-competitive inhibitor, PP242, will no doubt facilitate the design and synthesis of further catalytic mTOR inhibitors [108,109]. It is important to note that at this time there are no FDA approved drugs which specifically act on MNK kinases, and little progress has been made since the discovery of CGP57380, which exhibits low micromolar MNK inhibition [110]. Cercosporamide, a natural antifungal agent, was found to be a potent inhibitor of MNK1/2, in the nanomolar range. However, its broad-spectrum 
effects limit its uses as an effective treatment as it also inhibits a number of other kinases, including JAK3, GSK $3 \beta$, ALK4 and Pim1 at low micromolar potency (see Figure 4) [9,111,112].

The need for a multitargeted treatment regime has led to complex 'drug cocktails' being administered to patients. For example, a chemotherapy protocol known as 'CHOP' is used to treat non-Hodgkin lymphoma. This combination therapy consists of cyclophosphamide (immunosuppressant), hydroxydaunomycin (DNA intercalator), oncovin (antimitotic) and prednisolone (immunosuppressant steroid) [113]. Although often well-tolerated, combination therapies can have several drawbacks. These include poor patient compliance, drug-drug interactions and potentially severe side effects. The coformulation of multiple drugs into a single dosage improves patient compliance by simplifying dosing regiments, however, complex pharmacokinetic (PK) and pharmacodynamic (PD) relationships occur through the variation in metabolism rate among patients [101].

The focus has now shifted to the idea of a single chemical entity that comprises elements capable of inhibiting multiple biological targets. The complex nature of cancer has led to the concept of hybrid drugs, which act on multiple targets with the need to deliver more than one drug concurrently. Combination therapy involves the linking of two selected pharmacophores that act against different therapeutic intracellular targets simultaneously. This multihit hypothesis results in a synergistic affect and makes drug resistance less likely [41].

Hybrid drugs can be synthesized by 'blending' two pharmacophores with similar sub-structures together or by joining the separate compounds via noncleavable or cleavable linkers [102]. In the latter approach, using a labile linker such as an ester can result in the release of the two drugs when cleaved by plasma esterases [99]. The rationale behind the development of hybrid drugs is the simultaneous presence of chemical entities in the cell, which may act in a synergistic manner to augment potency and reduce side effects $[101,102,114]$. This is in contrast to the administration of individual drugs that will inevitably be delivered to the target site at different rates and efficacies. Hybrid compounds can often display improved bioavailability and present more predictable pharmacokinetic and pharmacodynamic profiles in comparison to individual agents [102,114].

There are limitations with hybrid drugs, as most of these compounds will violate both Veber et al. and Lipinksi's rules governing oral bioavailability
(A)

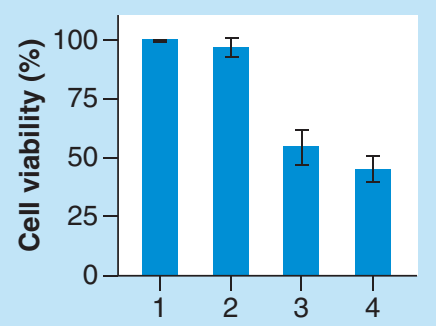

(C)

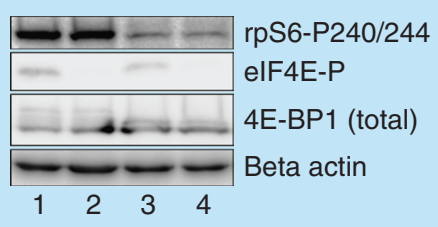

(B)

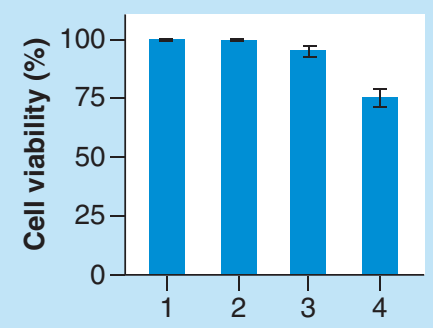

(D)

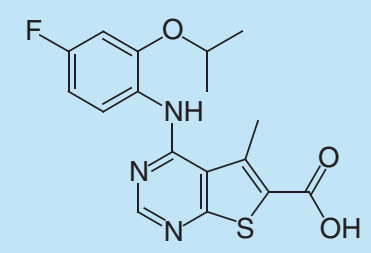

Figure 5. MNKI-19 and PP242 combination results in a synergistic cytotoxicity and has led to the development of a novel hybrid agent. (A \& B) Cell viability assay in MRC5 cells and T98G cells, respectively. Cells were treated with DMSO (1), MNKI-19 $1 \mu \mathrm{M}$ (2), PP242 $1 \mu \mathrm{M}$ (3) and a combination of MNKI-19/PP242 $1 \mu \mathrm{M}$ each (4) for $24 \mathrm{~h}$. Optimal concentrations of Mnk inhibitor, MNKI-19, were determined in prior experiments in accordance with Teo et al. (2015). Screening data also showed no effect of MNKI-19 on CDK2A or CDK9T1 kinases [110]. Cell viability was determined by CellTiter Blue assay. Data are presented as the means $\pm S D, n=3$. (C) Western blot analysis for the expression of elF4E-P, 4EBP1-P and rpS6 P-240/ 244 in MRC5 cells treated with DMSO (1), MNKI-19 (2), PP242 (3) and a combination of MNKI-19/ PP242 (4), as in Panel A for 24 hr, [E. Lineham, Unpublished data]. (D) Structure of MNKI-19. 
in particular by exceeding molecular weight, polar surface area and $\log \mathrm{P}$ values [115-117]. This means that administration may be limited to the IV or topical route, although poor aqueous solubility may be improved by using linkers that impart hydrophilicity, such as polyethylene glycol linkers [99]. The chemical stability of the linker is important in cleavable hybrid agents, as it should not be cleaved before reaching the target site. Another potential difficulty lies in the dosing, if the optimal ratio between conjugates is not $1: 1$ [102].

Currently, estramustine may be considered to be the only FDA-approved hybrid in the clinic and is used to treat advanced stage prostate cancer [99]. Nevertheless, there is a huge amount of excitement surrounding hybrid drugs and researchers are continuing to make progress with the development of novel agents. For example, HDAC inhibitors have been successful in the treatment of hematological malignancies, although have had limited therapeutic effect in solid tumors. Vorinostat recently failed as a monotherapy in a metastatic breast cancer clinical trial $[102,118]$. However, synergistic effects have been observed when HDAC inhibitors have been used in combination with other drugs, including a significant decrease in cell viability when used in conjunction with Sorafenib, a dual action VEGFR/PDGFR and RAF kinase inhibitor [119,120]. This has prompted the development of HDAC inhibitor containing hybrid agents, for example, a recently synthesized dual HDAC/VEGFR2 inhibitor [114]. Another promising agent, CUDC-101, developed by Curis, was found to simultaneously inhibit HDAC class I/II, EGFR and HER2 and exhibited antiproliferative effects in vitro and growth inhibition in various cancer xenograft models [121]. It is currently being investigated in combination with radiation and other agents such as cisplatin in HSNCC [122].

The synthesis of a dual action MNK/mTOR hybrid agent may be an effective option for inhibiting eIF4E phosphorylation and warrants further investigation. Preliminary experiments detailed in Figure 5, demonstrate that dual inhibition of MNK and mTOR led to a significant reduction in cell viability in both MRC5 fibroblast and T98G glioblastoma cell lines. Further analysis by western blotting shows potent inhibition of downstream targets; eIF4E-P, 4EBP1-P and rpS6 P-240/242 when both the MNK inhibitor, MNKI19, and an mTOR inhibitor, PP242, were used in a 1:1 mixture. These data, in agreement with the literature, support the potential benefit of linking the two inhibitors as a single chemical entity. The development of dual action hybrids, be they joined by a 'permanent' or cleavable linker, is a current theme in our laboratory and results will be published in due course.

\section{Conclusion \& future perspective}

The overexpression and deregulation of translation factors, in particular, eIF4E, have been linked to the pathogenesis of many aggressive human cancers. The phosphorylation of eIF4E by MNK1/2 kinase correlates with invasive and metastatic behavior, through the preferential translation of mitogenic proteins. eIF4E expression has also found to reflect the level of mesenchymal markers.

Experimental evidence has proven that the availability of eIF4E for translation can be repressed through the inhibition of mTORC1. Additionally, silencing MNK1/2 attenuates eIF4E phosphorylation and reduces the translation of mRNAs involved in metastasis. However, the independent suppression of either pathway induces complex feedback loops that stimulate activation of alternative pathways. eIF4E lies at the convergence point of both the mTOR and MNK/ eIF4E pathways, which provides an opportunity for dual targeting.

Personalized, multitargeted therapy is becoming increasingly popular. Hybrid molecules incorporate several moieties that bind to and inhibit different biological targets, delivering a double-blow to cells. In this regard, the complementary mTOR and MNK pathways are a promising target for such hybrid agents in the treatment of aggressive migratory cancers. Advances in the knowledge of PI3K/AKT/mTOR and MNK/eIF4E pathways in oncogenesis will contribute to the understanding of drug resistance. Furthermore, the expanding array of structural biology knowledge will aid rational drug design and enhance the drug discovery effort.

The benefits of hybrid drugs can clearly be observed; however, it is still a growing area of research and further development of these agents is required.

\section{Financial \& competing interests disclosure}

Studentship costs to E Lineham were funded by the School of Life Sciences, University of Sussex. This work was supported by the Biotechnology and Biological Sciences Research Council [grant no. BB/L018209/1]. All data supporting this study are included in the review article. The authors have no other relevant affiliations or financial involvement with any organization or entity with a financial interest in or financial conflict with the subject matter or materials discussed in the manuscript apart from those disclosed.

No writing assistance was utilized in the production of this manuscript.

\section{Open access}

This work is licensed under the Attribution-NonCommercialNoDerivatives 4.0 Unported License. To view a copy of this license, visit http://creativecommons.org/licenses/by-nc-nd/4.0/ 
Executive summary

\section{Translation initiation: an overview}

- Translation is essential for cellular homeostasis and is primarily regulated at the initiation stage. This process is coordinated by eukaryotic initiation factors and accessory proteins.

- elF4E forms part of the eIF4F complex required for the translation of mRNA.

elF4E \& its role in cancer

- The level of elF4E expression is crucial for cancer development. Overexpression leads to the translation of a subset of mRNAs that favor oncogenesis.

- The phosphorylated form of elF4E is correlated with an increase in mesenchymal markers and poor clinical outcome in human cancers.

- Targeting the translational machinery through the inhibition of elF4E is a promising therapeutic option for the treatment of aggressive metastatic cancers.

MAPK-interacting kinases

- MNK1/2 are serine/threonine protein kinases that phosphorylate eIF4E on serine 209, leading to the preferential translation of oncogenic proteins.

- MNK1/2 present an attractive potential therapeutic target as they are dispensable for normal development and act at the convergence point of P38MAPK and ERK pathways, commonly upregulated in cancer cells.

- The unique DFD motif and specific insertions in the catalytic domain distinguishes MNK1/2 from other protein kinases and provides a means for selective targeting.

mTOR

- $\mathrm{mTOR}$ is a Ser/Thr protein kinase and forms two multiprotein complexes: mTORC1 and mTORC2.

- mTORC1 is activated by multiple growth factors, insulin and nutrients through the PI3K/AKT pathway. mTORC1 plays a central role in stimulating protein synthesis through the phosphorylation of $4 \mathrm{E}$-binding proteins (4E-BPs) and p7056K.

\section{mTOR \& its role in cancer}

- Hyperactivity of the PI3K/AKT/mTOR pathway is a common feature of oncogenesis and enables the cancer cells to meet the demands of increased growth rate. mTOR is activated in approximately $70 \%$ of cancers.

- Activated mTOR positively regulates the translational landscape of cancer cells by increasing the translation of mRNAs involved in metastasis.

- Deregulation of the mTOR pathway is correlated with poor clinical outcome and drug resistance.

Interplay between the mTOR \& Mnk/elF4E pathways

- Evidence for a compensatory feedback mechanism linking the PI3K/AKT/mTOR pathway and the MNK/elF4E pathway has been reported both experimentally and clinically. Downregulation of one pathway correlated with the activation of the other, supporting cancer survival.

- Simultaneous inhibition of both pathways prevented feedback initiation in PC-3 and glioblastoma cell lines and blocked cell proliferation.

Therapeutic targeting \& the concept of hybrid inhibitors

- The heterogenous nature of cancer and the complexity of cellular signaling means that a single treatment approach is often ineffective and leads to drug resistance.

- Cancer patients often receive 'drug cocktails', a combination of drugs taken together as a multitargeted treatment. This approach can lead to complicated dosing regimens, poor patient compliance and drug-drug interactions.

- Hybrid drugs involve the linking of two pharmacophores that act against different intracellular targets concurrently. The simultaneous presence of chemical entities within the same cell may act synergistically to augment potency and therefore reduce the likelihood of drug resistance.

- The synthesis of a dual action MNK/mTOR hybrid agent may be an effective option in the treatment of highly migratory cancers through the inhibition of elF4E.

\section{References}

Papers of special note have been highlighted as: $\bullet$ of interest;

-• of considerable interest

1 Ruggero D. Translational control in cancer etiology. Cold Spring Harb. Perspect. Biol. 5(2), pii:a012336 (2013).

2 Morley SJ, Coldwell MJ, Clemens MJ. Initiation factor modifications in the preapoptotic phase. Cell Death Differ. 12(6), 571-584 (2005).
3 Tomoo K, Shen X, Okabe K et al. Crystal structures of 7-methylguanosine 5'-triphosphate-bound human full-length eukaryotic initiation factor $4 \mathrm{E}$ : biological importance of the C-terminal flexible region. Biochem. J. 362(Pt 3), 539-544 (2002).

4 Sonenberg N, Hinnebusch AG. Regulation of translation initiation in eukaryotes: mechanisms and biological targets. Cell 136(4), 731-745 (2009). 
5 Mamane Y, Petroulakis E, Lebacquer O, Sonenberg N. mTOR, translation initiation and cancer. Oncogene 25(48), 6416-6422 (2006).

6 Klann E, Dever TE. Biochemical mechanisms for translational regulation in synaptic plasticity. Nat. Rev. Neurosci. 5(12), 931-942 (2004).

7 Truitt ML, Conn CS, Shi Z et al. Differential requirements for eIF4E dose in normal development and cancer. Cell 162(1), 59-71 (2015).

8 Truitt ML, Ruggero D. New frontiers in translational control of the cancer genome. Nat. Rev. Cancer 17(5), 332 (2017).

9 Hou J, Lam F, Proud C, Wang S. Targeting Mnks for cancer therapy. Oncotarget 3(2), 118-131 (2012).

- The role of Mnks in cancer.

10 Graff JR, Konicek BW, Carter JH, Marcusson EG. Targeting the eukaryotic translation initiation factor $4 \mathrm{E}$ for cancer therapy. Cancer Res. 68(3), 631-634 (2008).

11 Lu C, Makala L, Wu D, Cai Y. Targeting translation: eIF4E as an emerging anticancer drug target. Expert Rev. Mol. Med. 18, e2 (2016).

12 Grzmil M, Huber RM, Hess D et al. MNK1 pathway activity maintains protein synthesis in rapalog-treated gliomas. J. Clin. Invest. 124(2), 742-754 (2014).

13 Feoktistova K, Tuvshintogs E, Do A, Fraser CS. Human eIF4E promotes mRNA restructuring by stimulating eIF4A helicase activity. Proc. Natl Acad. Sci. USA 110(33), 13339-13344 (2013).

14 Liu T, Li R, Zhao $\mathrm{H}$ et al. eIF4E promotes tumorigenesis and modulates chemosensitivity to cisplatin in esophageal squamous cell carcinoma. Oncotarget 7(41), 66851-66864 (2016).

15 Asimomytis A, Karanikou M, Rodolakis A et al. mTOR downstream effectors, 4EBP1 and eIF4E, are overexpressed and associated with HPV status in precancerous lesions and carcinomas of the uterine cervix. Oncol. Lett. 12(5), 3234-3240 (2016).

16 Van Der Kelen K, Beyaert R, Inze D, De Veylder L. Translational control of eukaryotic gene expression. Crit. Rev. Biochem. Mol. Biol. 44(4), 143-168 (2009).

17 Sonenberg N, Dever TE. Eukaryotic translation initiation factors and regulators. Curr. Opin. Struct. Biol. 13(1), 56-63 (2003).

18 Thumma SC, Jacobson BA, Patel MR et al. Antisense oligonucleotide targeting eukaryotic translation initiation factor $4 \mathrm{E}$ reduces growth and enhances chemosensitivity of non-small-cell lung cancer cells. Cancer Gene Ther. 22(8), 396-401 (2015).

19 Garcia-Recio EM, Pinto-Diez C, Perez-Morgado MI et al. Characterization of MNK1b DNA aptamers that inhibit proliferation in MDA-MB231 breast cancer cells. Mol. Ther. Nucleic Acids 5, e275 (2016).

20 Phillips A, Blaydes JP. MNK1 and EIF4E are downstream effectors of MEKs in the regulation of the nuclear export of HDM2 mRNA. Oncogene 27(11), 1645-1649 (2008).

21 Joshi S, Platanias LC. Mnk kinase pathway: cellular functions and biological outcomes. World J. Biol. Chem. 5(3), 321-333 (2014).
22 Bhat M, Robichaud N, Hulea L, Sonenberg N, Pelletier J, Topisirovic I. Targeting the translation machinery in cancer. Nat. Rev. Drug Discov. 14(4), 261-278 (2015).

-• Important review on translational machinery in cancer.

23 Mamane Y, Petroulakis E, Martineau Y et al. Epigenetic activation of a subset of mRNAs by eIF4E explains its effects on cell proliferation. PLoS ONE 2(2), e242 (2007).

24 Li Z, Sun Y, Qu M, Wan H, Cai F, Zhang P. Inhibiting the MNK-eIF4E-beta-catenin axis increases the responsiveness of aggressive breast cancer cells to chemotherapy. Oncotarget 8(2), 2906-2915 (2017).

25 Beggs JE, Tian S, Jones GG et al. The MAP kinaseinteracting kinases regulate cell migration, vimentin expression and eIF4E/CYFIP1 binding. Biochem. J. 467(1), 63-76 (2015).

- The role of Mnks in cell migration.

26 Robichaud N, Del Rincon SV, Huor B et al. Phosphorylation of eIF4E promotes EMT and metastasis via translational control of SNAIL and MMP-3. Oncogene 34(16), 2032-2042 (2015).

27 Avdulov S, Li S, Michalek V et al. Activation of translation complex eIF4F is essential for the genesis and maintenance of the malignant phenotype in human mammary epithelial cells. Cancer Cell 5(6), 553-563 (2004).

28 Lazaris-Karatzas A, Montine KS, Sonenberg N. Malignant transformation by a eukaryotic initiation factor subunit that binds to mRNA 5' cap. Nature 345(6275), 544-547 (1990).

29 Gao M, Zhang X, Li D, He P, Tian W, Zeng B. Expression analysis and clinical significance of eIF4E, VEGF-C, E-cadherin and MMP-2 in colorectal adenocarcinoma. Oncotarget 7(51), 85502-85514 (2016).

30 Wendel HG, Silva RL, Malina A et al. Dissecting eIF4E action in tumorigenesis. Genes Dev. 21(24), 3232-3237 (2007).

31 Chaffer CL, Weinberg RA. A perspective on cancer cell metastasis. Science 331(6024), 1559-1564 (2011).

32 Willett M, Brocard M, Davide A, Morley SJ. Translation initiation factors and active sites of protein synthesis co-localize at the leading edge of migrating fibroblasts. Biochem. J. 438(1), 217-227 (2011).

33 Zaytseva YY, Valentino JD, Gulhati P, Evers BM. mTOR inhibitors in cancer therapy. Cancer Lett. 319(1), 1-7 (2012).

34 Parsons JT, Horwitz AR, Schwartz MA. Cell adhesion: integrating cytoskeletal dynamics and cellular tension. Nat. Rev. Mol. Cell Biol. 11(9), 633-643 (2010).

35 Ridley AJ. Rho proteins, PI 3-kinases, and monocyte/ macrophage motility. FEBS Lett. 498(2-3), 168-171 (2001).

36 Zhou FF, Yan M, Guo GF et al. Knockdown of eIF4E suppresses cell growth and migration, enhances chemosensitivity and correlates with increase in $\mathrm{Bax} / \mathrm{Bcl}-2$ ratio in triple-negative breast cancer cells. Med. Oncol. 28(4), 1302-1307 (2011).

37 Mackay CR. Moving targets: cell migration inhibitors as new anti-inflammatory therapies. Nat. Immunol. 9(9), 988-998 (2008). 

is a YB-1 target gene responsible for imparting trastuzumab resistance and can be blocked by RSK inhibition. Oncogene 31(41), 4434-4446 (2012).

39 Pyronnet S, Imataka H, Gingras AC, Fukunaga R, Hunter T, Sonenberg N. Human eukaryotic translation initiation factor $4 \mathrm{G}$ recruits mnk1 to phosphorylate eIF4E. EMBO J. 18(1), 270-279 (1999).

Furic L, Rong L, Larsson O et al. eIF4E phosphorylation promotes tumorigenesis and is associated with prostate cancer progression. Proc. Natl Acad. Sci. USA 107(32), 14134-14139 (2010).

41 Grzmil M, Morin P Jr, Lino MM et al. MAP kinaseinteracting kinase 1 regulates SMAD2-dependent TGF-beta signaling pathway in human glioblastoma. Cancer Res. 71(6), 2392-2402 (2011).

42 Bianchini A, Loiarro M, Bielli P et al. Phosphorylation of eIF4E by MNKs supports protein synthesis, cell cycle progression and proliferation in prostate cancer cells. Carcinogenesis 29(12), 2279-2288 (2008).

43 Diab S, Li P, Basnet SK et al. Unveiling new chemical scaffolds as Mnk inhibitors. Future Med. Chem. 8(3), 271-285 (2016).

44 Kosciuczuk EM, Saleiro D, Kroczynska B et al. Merestinib blocks Mnk kinase activity in acute myeloid leukemia progenitors and exhibits antileukemic effects in vitro and in vivo. Blood 128(3), 410-414 (2016).

45 O'loghlen A, Gonzalez VM, Salinas M, Martin ME. Suppression of human Mnk1 by small interfering RNA increases the eukaryotic initiation factor $4 \mathrm{~F}$ activity in HEK293T cells. FEBS Lett. 578(1-2), 31-35 (2004). Hollingsworth R, Weiner MP. Identification of the human $M n k 2$ gene through protein interaction with estrogen receptor beta. Genomics 69(1), 63-71 (2000). mitogen-activated protein kinase signal-integrating kinase Mnk2 is a eukaryotic initiation factor 4E kinase with high levels of basal activity in mammalian cells. Mol. Cell. Biol. 21(3), 743-754 (2001).

48 Ueda T, Watanabe-Fukunaga R, Fukuyama H, Nagata $S$, Fukunaga R. Mnk2 and Mnk1 are essential for constitutive and inducible phosphorylation of eukaryotic initiation factor $4 \mathrm{E}$ but not for cell growth or development. Mol. Cell. Biol. 24(15), 6539-6549 (2004).

49 Diab S, Kumarasiri M, Yu M et al. MAP kinase-interacting kinases - emerging targets against cancer. Chem. Biol. 21(4), 441-452 (2014).

50 Stead RL, Proud CG. Rapamycin enhances eIF4E phosphorylation by activating MAP kinase-interacting kinase 2a. FEBS Lett. 587(16), 2623-2628 (2013).

51 Bramham CR, Jensen KB, Proud CG. Tuning specific translation in cancer metastasis and synaptic memory: control at the MNK-eIF4E Axis. Trends Biochem. Sci. 41(10), 847-858 (2016).

52 Fan W, Wang W, Mao X et al. Elevated levels of p-Mnk1, p-eIF4E and p-p70S6K proteins are associated with tumor recurrence and poor prognosis in astrocytomas. J. Neurooncol. 131(3), 485-493 (2016).

- Evidence for the overexpression of p-Mnk1, p-eIF4E and p-p70S6K in cancer.

53 Diab S, Teo T, Kumarasiri M et al. Discovery of 5-(2-(phenylamino) pyrimidin-4-yl)thiazol-2(3H)-one derivatives as potent Mnk2 inhibitors: synthesis, SAR analysis and biological evaluation. ChemMedChem 9(5), 962-972 (2014).

54 Ueda T, Sasaki M, Elia AJ et al. Combined deficiency for MAP kinase-interacting kinase 1 and 2 delays tumor development. Proc. Natl Acad. Sci. USA 107(32), 13984-13990 (2010).

55 Teo T, Yu M, Yang Y et al. Pharmacologic co-inhibition of Mnks and mTORC1 synergistically suppresses proliferation and perturbs cell cycle progression in blast crisis-chronic myeloid leukemia cells. Cancer Lett. 357(2), 612-623 (2015).

56 Altman JK, Szilard A, Konicek BW et al. Inhibition of Mnk kinase activity by cercosporamide and suppressive effects on acute myeloid leukemia precursors. Blood 121(18), 3675-3681 (2013)

57 Oyarzabal J, Zarich N, Albarran MI et al. Discovery of mitogen-activated protein kinase-interacting kinase 1 inhibitors by a comprehensive fragment-oriented virtual screening approach. J. Med. Chem. 53(18), 6618-6628 (2010).

58 Kannan S, Poulsen A, Yang HY et al. Probing the binding mechanism of Mnk inhibitors by docking and molecular dynamics simulations. Biochemistry 54(1), 32-46 (2015).

59 Sebolt-Leopold JS, English JM. Mechanisms of drug inhibition of signalling molecules. Nature 441(7092), 457-462 (2006).

60 Hou J, Teo T, Sykes MJ, Wang S. Insights into the importance of DFD-motif and insertion I1 in stabilizing the DFD-out conformation of Mnk2 kinase. ACS Med. Chem. Lett. 4(8), 736-741 (2013).

61 Jauch R, Jakel S, Netter C et al. Crystal structures of the Mnk2 kinase domain reveal an inhibitory conformation and a zinc binding site. Structure 13(10), 1559-1568 (2005).

62 Wang Q, Wei F, Li C et al. Combination of mTOR and EGFR kinase inhibitors blocks mTORC1 and mTORC2 kinase activity and suppresses the progression of colorectal carcinoma. PLoS ONE 8(8), e73175 (2013).

63 Hsieh AC, Liu Y, Edlind MP et al. The translational landscape of mTOR signalling steers cancer initiation and metastasis. Nature 485(7396), 55-61 (2012).

- Highlights the role of mTOR in oncogenesis.

64 Morita M, Gravel SP, Hulea L et al. mTOR coordinates protein synthesis, mitochondrial activity and proliferation. Cell Cycle 14(4), 473-480 (2015).

65 Merrick WC. eIF4F: a retrospective. J. Biol. Chem. 290(40), 24091-24099 (2015).

66 Hsieh AC, Ruggero D. Targeting eukaryotic translation initiation factor 4E in cancer. Clin. Cancer Res. 16(20), 4914-4920 (2010)

- Background on eIF4E in relation to cancer. 
67 Laplante M, Sabatini DM. mTOR signaling in growth control and disease. Cell 149(2), 274-293 (2012).

68 Qin X, Jiang B, Zhang Y. 4E-BP1, a multifactor regulated multifunctional protein. Cell Cycle 15(6), 781-786 (2016).

69 Showkat M, Beigh MA, Andrabi KI. mTOR signaling in protein translation regulation: implications in cancer genesis and therapeutic interventions. Mol. Biol. Int. 2014, 686984 (2014).

70 Zhang H, Dou J, Yu Y et al. mTOR ATP-competitive inhibitor INK128 inhibits neuroblastoma growth via blocking mTORC signaling. Apoptosis 20 (1), 50-62 (2015).

71 Jhanwar-Uniyal M, Amin AG, Cooper JB, Das K, Schmidt $\mathrm{MH}$, Murali R. Discrete signaling mechanisms of mTORC1 and mTORC2: connected yet apart in cellular and molecular aspects. Adv. Biol. Regul. 64, 39-48 (2017).

72 Holz MK, Ballif BA, Gygi SP, Blenis J. mTOR and S6K1 mediate assembly of the translation preinitiation complex through dynamic protein interchange and ordered phosphorylation events. Cell 123(4), 569-580 (2005).

73 Wang T, Bray SM, Warren ST. New perspectives on the biology of fragile X syndrome. Curr. Opin. Genet. Dev. 22(3), 256-263 (2012).

74 Guertin DA, Sabatini DM. Defining the role of mTOR in cancer. Cancer Cell 12(1), 9-22 (2007).

75 Cope CL, Gilley R, Balmanno K et al. Adaptation to mTOR kinase inhibitors by amplification of eIF4E to maintain capdependent translation. J. Cell Sci. 127(Pt 4), 788-800 (2014).

76 Chiarini F, Evangelisti C, Mccubrey JA, Martelli AM. Current treatment strategies for inhibiting $\mathrm{mTOR}$ in cancer. Trends Pharmacol. Sci. 36(2), 124-135 (2015).

77 Eltschinger S, Loewith R. TOR complexes and the maintenance of cellular homeostasis. Trends Cell Biol. 26(2), 148-159 (2016).

78 Gaubitz C, Prouteau M, Kusmider B, Loewith R. TORC2 structure and function. Trends Biochem. Sci. 41(6), 532-545 (2016).

79 Bozulic L, Hemmings BA. PIKKing on PKB: regulation of PKB activity by phosphorylation. Curr. Opin. Cell Biol. 21(2), 256-261 (2009).

80 Hay N. Mnk earmarks eIF4E for cancer therapy. Proc. Natl Acad. Sci. USA 107(32), 13975-13976 (2010).

81 Gandin V, Masvidal L, Hulea L et al. nanoCAGE reveals 5' UTR features that define specific modes of translation of functionally related MTOR-sensitive mRNAs. Genome Res. 26(5), 636-648 (2016).

82 Gandin V, Masvidal L, Cargnello M et al. mTORC1 and CK2 coordinate ternary and eIF4F complex assembly. Nat. Commun. 7, 11127 (2016).

83 Alain T, Morita M, Fonseca BD et al. eIF4E/4E-BP ratio predicts the efficacy of mTOR targeted therapies. Cancer Res. 72(24), 6468-6476 (2012).

84 Slotkin EK, Patwardhan PP, Vasudeva SD, De Stanchina E, Tap WD, Schwartz GK. MLN0128, an ATPcompetitive mTOR kinase inhibitor with potent in vitro and in vivo antitumor activity, as potential therapy for bone and soft-tissue sarcoma. Mol. Cancer Ther. 14(2), 395-406 (2015)
85 Gulhati P, Bowen KA, Liu J et al. mTORC1 and mTORC2 regulate EMT, motility, and metastasis of colorectal cancer via RhoA and Rac1 signaling pathways. Cancer Res. 71(9), 3246-3256 (2011).

86 Tiwari N, Gheldof A, Tatari M, Christofori G. EMT as the ultimate survival mechanism of cancer cells. Semin. Cancer Biol. 22(3), 194-207 (2012).

87 Saxton RA, Sabatini DM. mTOR signaling in growth, metabolism, and disease. Cell 169(2), 361-371 (2017).

- Describes recent advances in mTOR function, regulation and therapeutic targeting.

88 Steelman LS, Martelli AM, Cocco L et al. The therapeutic potential of mTOR inhibitors in breast cancer. Br. J. Clin. Pharmacol. 82(5), 1189-1212 (2016).

89 Populo H, Lopes JM, Soares P. The mTOR signalling pathway in human cancer. Int. J. Mol. Sci. 13(2), 1886-1918 (2012).

90 Liu Q, Kirubakaran S, Hur W et al. Kinome-wide selectivity profiling of ATP-competitive mammalian target of rapamycin inhibitors and characterization of their binding kinetics. J. Biol. Chem. 287(13), 9742-9752 (2012).

91 Aylett CH, Sauer E, Imseng S et al. Architecture of human mTOR complex 1. Science 351(6268), 48-52 (2016).

92 Wang X, Yue P, Chan CB et al. Inhibition of mammalian target of rapamycin induces phosphatidylinositol 3-kinasedependent and Mnk-mediated eukaryotic translation initiation factor 4E phosphorylation. Mol. Cell. Biol. 27(21), 7405-7413 (2007).

93 Marzec M, Liu X, Wysocka M, Rook AH, Odum N, Wasik MA. Simultaneous inhibition of mTOR-containing complex 1 cells. PLoS ONE 6(9), e24849 (2011).

94 Zang C, Eucker J, Liu H, Muller A, Possinger K, Scholz CW. Concurrent inhibition of PI3-kinase and mTOR induces cell death in diffuse large $\mathrm{B}$ cell lymphomas, a mechanism involving down regulation of Mcl-1. Cancer Lett. 339(2), 288-297 (2013).

95 Sun SY, Rosenberg LM, Wang X et al. Activation of Akt and eIF4E survival pathways by rapamycin-mediated mammalian target of rapamycin inhibition. Cancer Res. 65(16), 7052-7058 (2005).

96 Gilley R, Balmanno K, Cope CL, Cook SJ. Adaptation to chronic mTOR inhibition in cancer and in aging. Biochem. Soc. Trans. 41(4), 956-961 (2013).

97 Mazan-Mamczarz K, Peroutka RJ, Steinhardt JJ et al. Distinct inhibitory effects on mTOR signaling by ethanol and INK128 in diffuse large B-cell lymphoma. Cell Commun. Signal. 13, 15 (2015).

98 Wen Q, Wang W, Luo J et al. CGP57380 enhances efficacy of RAD001 in non-small cell lung cancer through abrogating mTOR inhibition-induced phosphorylation of eIF4E and activating mitochondrial apoptotic pathway. Oncotarget 7(19), 27787-27801 (2016).

99 Gediya LK, Njar VC. Promise and challenges in drug discovery and development of hybrid anticancer drugs. Expert Opin. Drug Discov. 4(11), 1099-1111 (2009).

100 Fan QW, Knight ZA, Goldenberg DD et al. A dual PI3 kinase/mTOR inhibitor reveals emergent efficacy in glioma. Cancer Cell 9(5), 341-349 (2006). 
101 Bansal Y, Silakari O. Multifunctional compounds: smart molecules for multifactorial diseases. Eur. J. Med. Chem. 76 31-42 (2014)

102 De Lera AR, Ganesan A. Epigenetic polypharmacology: from combination therapy to multitargeted drugs. Clin. Epigenetics 8105 (2016).

-. Important review on combination treatment and the concept of hybrid drugs.

103 Polivka J Jr, Janku F. Molecular targets for cancer therapy in the PI3K/AKT/mTOR pathway. Pharmacol. Ther. 142(2), 164-175 (2014).

104 Efeyan A, Sabatini DM. mTOR and cancer: many loops in one pathway. Curr. Opin. Cell Biol. 22(2), 169-176 (2010).

105 Basnet SK, Diab S, Schmid R et al. Identification of a highly conserved allosteric binding site on Mnk1 and Mnk2. Mol. Pharmacol. 88(5), 935-948 (2015).

106 Wu P, Nielsen TE, Clausen MH. Small-molecule kinase inhibitors: an analysis of FDA-approved drugs. Drug Discov. Today 21(1), 5-10 (2016).

107 Zhao Z, Wu H, Wang L et al. Exploration of type II binding mode: a privileged approach for kinase inhibitor focused drug discovery? ACS Chem. Biol. 9(6), 1230-1241 (2014).

108 Rodrik-Outmezguine VS, Okaniwa M, Yao Z et al. Overcoming mTOR resistance mutations with a newgeneration mTOR inhibitor. Nature 534(7606), 272-276 (2016).

109 Yang H, Rudge DG, Koos JD, Vaidialingam B, Yang HJ, Pavletich NP. mTOR kinase structure, mechanism and regulation. Nature 497(7448), 217-223 (2013).

110 Teo T, Yang Y, Yu M et al. An integrated approach for discovery of highly potent and selective Mnk inhibitors: screening, synthesis and SAR analysis. Eur. J. Med. Chem. 103, 539-550 (2015).

111 Liu Y, Sun L, Su X, Guo S. Inhibition of eukaryotic initiation factor $4 \mathrm{E}$ phosphorylation by cercosporamide selectively suppresses angiogenesis, growth and survival of human hepatocellular carcinoma. Biomed. Pharmacother. 84, 237-243 (2016).

112 Konicek BW, Stephens JR, Mcnulty AM et al. Therapeutic inhibition of MAP kinase interacting kinase blocks eukaryotic initiation factor $4 \mathrm{E}$ phosphorylation and suppresses outgrowth of experimental lung metastases. Cancer Res. 71(5), 1849-1857 (2011).
113 Fisher RI, Gaynor ER, Dahlberg S et al. Comparison of a standard regimen with three intensive chemotherapy regimens for advanced non-Hodgkin's lymphoma. N. Engl. J. Med. 328(14), 1002-1006 (1993).

114 Patel H, Chuckowree I, Coxhead P et al. Synthesis of hybrid anticancer agents based on kinase and histone deacetylase inhibitors. MedChem Comm 5(12), 1829-1833 (2014).

115 Lipinski CA. Drug-like properties and the causes of poor solubility and poor permeability. J. Pharmacol. Toxicol. Methods 44(1), 235-249 (2000).

116 Lipinski CA, Lombardo F, Dominy BW, Feeney PJ. Experimental and computational approaches to estimate solubility and permeability in drug discovery and development settings. Adv. Drug Deliv. Rev. 46(1-3), 3-26 (2001).

117 Veber DF, Johnson SR, Cheng HY, Smith BR, Ward KW, Kopple KD. Molecular properties that influence the oral bioavailability of drug candidates. J. Med. Chem. 45(12), 2615-2623 (2002).

118 Luu TH, Morgan RJ, Leong L et al. A Phase II trial of vorinostat in metastatic breast cancer: a California Cancer Consortium study. Clin. Cancer. Res. 14(21), 7138-7142 (2008).

119 Park MA, Mitchell C, Zhang G et al. Vorinostat and sorafenib increase CD95 activation in gastrointestinal tumor cells through a $\mathrm{Ca}(2+)$-de novo ceramide-PP2A-reactive oxygen species-dependent signaling pathway. Cancer Res. 70 (15), 6313-6324 (2010).

120 Pastore F, Levine RL. Epigenetic regulators and their impact on therapy in acute myeloid leukemia. Haematologica 101(3), 269-278 (2016).

121 Rana A, Alex JM, Chauhan M, Joshi G, Kumar R. A review on pharmacophoric designs of antiproliferative agents. Med. Chem. Res. 24(3), 903-920 (2015).

122 Galloway TJ, Wirth LJ, Colevas AD et al. A Phase I Study of CUDC-101, a multitarget inhibitor of HDACs, EGFR, and HER2, in combination with chemoradiation in patients with head and neck squamous cell carcinoma. Clin. Cancer. Res. 21(7), 1566-1573 (2015).

123 Pettersen EF, Goddard TD, Huang CC et al. UCSF chimera - a visualization system for exploratory research and analysis. J. Comput. Chem. 25(13), 1605-1612 (2004). 